\title{
A INTUIÇÃO DE CRIANÇAS E ADULTOS NA INTERPRETAÇÃO DOS NUMERAIS: uma questão semântica ou pragmática?
}

\author{
THE INTUITION OF CHILDREN AND ADULTS IN THE INTERPRETATION OF THE \\ NUMERALS: \\ a pragmatic or semantic question?
}

\author{
Carine Haupt \\ Doutoranda em Lingüística - UFSC - CAPES \\ Leandra Cristina de Oliveira \\ Doutoranda em Lingüística - UFSC - CAPES
}

\begin{abstract}
Resumo
Neste artigo, propomos uma discussão sobre a interpretação que os indivíduos fazem dos numerais. Conforme a teoria neo-griceana, 'um número x' significa 'pelo menos x', e a interpretação 'exatamente $x$ ' é concebida pragmaticamente. Em contrapartida, há estudos que contestam essa abordagem, defendendo que 'um número $x$ ' significa 'exatamente x'. Determinados contextos, entretanto, podem gerar a interpretação de 'pelo menos x'. Deste modo, a fim de avaliar a adequação dessas propostas, aplicamos um teste a crianças e adultos, averiguando através dos resultados: i) se o numeral pode gerar diferentes interpretações conforme o contexto em que ele está inserido e ii) se crianças e adultos interpretam da mesma forma os numerais. Em seguida, relacionamos os resultados com as teorias apresentadas.
\end{abstract}

Palavras-chave: Números. Interpretação semântica. Inferência pragmática.

\begin{abstract}
In this paper, we discuss about the interpretation that individuals ascribe to numerals. For the neo-Gricean theory, a 'number $\mathrm{x}$ ' means 'at least $\mathrm{x}$ ', and interpretation 'exactly $x$ ' is conceived pragmatically. On the other hand, there are studies that contest this aproach, defending that a 'number $x$ ' means 'exactly x', and that in certain contexts the interpretation of 'at least $X$ ' can be generated. In order to verify which theory is more adequadte, we applied a test with children and adult, inquiring through the results: i) if the numeral can generate different interpretations in agreement the context where it is inserted and ii) if children and adults interpret in the same way the numerals. After that, we relate the results with the presented theories.
\end{abstract}

Keywords: Numbers. Semantics interpretation. Pragmatic inference.

\section{INTRODUÇÃO}

A discussão sobre o significado dos numerais é tema presente tanto na área da Semântica quanto na área da Pragmática. É natural, portanto, que esses diferentes olhares impliquem teorias conflitantes, motivando-nos a verificar, a partir da aplicação de testes, qual pode ser mais pertinente. Desse modo, esta investigação justifica-se pela 
necessidade de observar dados empíricos a fim de analisar questões teóricas sobre a semântica dos numerais ${ }^{1}$.

Conforme já mencionado, as teorias a respeito da semântica dos numerais não são unívocas. Sentenças com um numeral podem gerar diferentes interpretações, conforme apresentamos a seguir:

(1) João tem cinco filhos.

(1') João tem pelo menos cinco filhos.

(1') João tem exatamente cinco filhos.

Segundo a abordagem neo-griceana, a qual apresentamos na seção $\mathrm{I}$, um número $\mathrm{x}$ significa, semanticamente, 'pelo menos x', conforme a interpretação em (1'). Logo, se João tem seis filhos, a sentença em (1) não será falsa, uma vez que cinco significa 'pelo menos cinco'.

Contestando os neo-griceanos, Geurts (2006) afirma que um número x significa, $a$ priori, 'exatamente x'. Dessa forma, se João tem seis filhos, a sentença em (1) pode ser falsa. Veremos, na seção II, que a discussão proposta por Geurts é um pouco mais complexa. Segundo o autor, ainda que tenham o significado primário de 'exatamente' (exactly), na verdade, os números são polissêmicos, isto é, determinados contextos podem gerar a interpretação de 'pelo menos' (at least).

Muitos falantes, por intuição, defenderiam a segunda teoria, afirmando que, quando dizem um número qualquer, é exatamente a esse número que eles querem fazer referência. É difícil admitir, por exemplo, que ao proferir 'João tem dois filhos' o falante tenha, na verdade, três filhos. A interpretação mais imediata, nesse caso, é que o falante está sendo cooperativo, dando a informação exata do número de filhos que João tem.

Um contra-argumento, contudo, seriam sentenças do tipo 'Toda família com dois filhos tem direito à bolsa família', em que, indubitavelmente, 'dois' não quer dizer 'exatamente dois'. Será que as famílias com mais de dois filhos perderiam tal direito? É bem possível que não, já que quanto maior a quantidade de filhos maior a necessidade do benefício. ${ }^{2}$

A questão é saber, então, o que nos leva a interpretar os números de diferentes maneiras: ora como 'exatamente x', ora como 'pelo menos x', ora como 'no máximo x'. A discussão sobre a teoria de Levinson (2000) e de Geurts (2006), apresentada na seção II e III, bem como a análise dos resultados do teste aplicado em crianças e adultos talvez possam nos fornecer pistas sobre a interpretação que os falantes têm dos numerais. Antes, porém, abrimos um parêntese para tratar da questão das implicaturas - tema que será retomado na discussão do trabalho de Levinson (2000).

\footnotetext{
1 Essas questões foram discutidas no Seminário de Especialidade em Semântica: a interface semântica/pragmática, oferecido pela Professora Dra. Roberta Pires de Oliveira, no Programa de Pósgraduação em Lingüística da Universidade Federal de Santa Catarina (2007/2).

${ }^{2}$ Em países com controle de natalidade, como a China, seria possível a interpretação de 'exatamente dois' (ou 'no máximo dois'). Entretanto, como esse não é o caso do Brasil, parece que a interpretação de 'pelo menos dois' é mais pertinente. A interpretação de 'no máximo', contudo, não pode ser descartada. Em 'você pode comer duas bolachas', por exemplo, a interpretação mais evidente é a de 'no máximo'.
} 


\section{IMPLICATURAS CONVENCIONAIS CONVERSACIONAIS \\ VS. \\ IMPLICATURAS}

Grice (1967) divide duas classes de implicaturas: as implicaturas convencionais e as implicaturas conversacionais. A primeira está diretamente relacionada ao que é dito, isto é, "a significação convencional das palavras usadas determinará o que é implicitado." (GRICE, 1967, p. 85). Vejamos o exemplo a seguir:

(2) Ele é um inglês; ele é, portanto, um bravo.

Segundo o autor, ao proferir esta sentença, o falante compromete-se com o significado de suas palavras: o fato de ele ser um bravo é conseqüência do fato de ele ser um inglês. Entretanto, ainda que o falante não tenha dito explicitamente que ser um inglês significa ser um bravo, esta idéia é convencionalmente implicitada.

As implicaturas conversacionais, por outro lado, não dependem da forma, isto é, são raciocínios inferenciais conectados com o discurso (GRICE, 1967, p. 86). Segundo o autor, essas implicaturas são acionadas quando uma das máximas do Princípio de Cooperação ${ }^{3}$ não é respeitada explicitamente - se o falante viola uma máxima sem motivo para não estar sendo cooperativo, ele tem a intenção que seu interlocutor perceba que ele está implicando algo que não está expresso no que foi dito. Logo, Grice caracteriza as implicaturas conversacionais da seguinte forma:

i) o falante diz que $p$;

ii) não há nenhuma razão para o ouvinte supor que o Princípio de Cooperação não esteja sendo respeitado;

iii) o falante não poderia estar dizendo $p$ a não ser que pense $q$;

iv) o falante sabe que o ouvinte pode ver a suposição de que ele pensa que $q$ é necessário;

v) o falante não dá qualquer passo para impedir que o ouvinte pense $q$;

vi) logo, o falante tem a intenção de que o ouvinte pense $q$.

A seguir, apresentamos exemplos em que o falante abandona uma máxima a fim de que seu ouvinte gere uma implicatura conversacional.

a) Abandono da máxima da Quantidade: um indivíduo Y escreve uma carta de recomendação de seu aluno para uma vaga de emprego para professor de filosofia. O conteúdo da carta é: 'Prezado senhor, o conhecimento de inglês do senhor X é excelente, ele tem participado regularmente das nossas aulas. Sem mais, etc.' Segundo Grice (1967), não há porque duvidar da intenção do indivíduo Y em ser cooperativo, uma vez que ele se predispôs a escrever a carta. Não se pode duvidar, inclusive, que Y não tenha condição de dizer mais a respeito de $X$, já que este é seu aluno. Logo, ao abandonar a máxima da Quantidade, dando menos informações que seu interlocutor esperaria, o falante deve 'estar desejando dar informações que não deseja colocar por

\footnotetext{
${ }^{3}$ As máximas dizem respeito às categorias de quantidade, qualidade, relação e modo. Princípio de Cooperação: "faça sua contribuição conversacional tal como é requerida, no momento em que ocorre, pelo propósito ou direção do intercâmbio conversacional em que você está engajado" (GRICE, 1967, p. 86).
} 
escrito' (GRICE, 1967, p. 95). Ao dizer $p$ (X é fluente em inglês), o falante quer, na verdade, que o ouvinte entenda $q$. Neste caso, $q$ implica, hipoteticamente, que $\mathrm{X}$ não é um bom filósofo.

b) Abandono da máxima da Qualidade: X revela um segredo de Y a um concorrente deste. Em uma conversa, na qual todos os participantes sabem da traição de X, Y diz: 'X é um excelente amigo.' Se Y disse algo no qual ele não crê, $Y$ 'deve estar tentando comunicar alguma outra proposição que não a que parece estar dizendo. Tal proposição deve ser obviamente relacionada com a que parece estar dizendo' (GRICE, 1967, p. 96). Na verdade, ao proferir $p$ (X é um excelente amigo), o falante quer que seus ouvintes interpretem $q$-provavelmente, que X é um péssimo amigo.

Em suma, o termo implicatura remete a uma inferência que não faz parte do que é dito, isto é, a interpretação do proferimento vai além do significado daquilo que é expresso. Vale ressaltar que a implicatura deve estar relacionada com aquilo que é proferido, conforme lembra Grice (1967). Sem essa observação, corre-se o risco de inferir que todos os fenômenos pragmáticos são implicaturas.

É importante diferenciar, ainda, as implicaturas conversacionais generalizadas das implicaturas conversacionais particularizadas. Estas, segundo Grice (1967), são veiculadas a partir de um contexto específico. A situação a seguir exemplifica a afirmação do autor:

(3) A senhora X cantou 'Home sweet home'.

(4) A senhora $X$ produziu uma série de sons que correspondem exatamente à partitura de 'Home sweet home'.

Ao escolher a sentença em (4), é bastante provável que o falante tenha alguma intenção, uma vez que a sentença em (3) parece muito mais simples e concisa. Na hipótese desse falante ser um crítico musical, deduz-se que ele espera que o ouvinte interprete que a atuação da 'senhora $X$ ' não foi suficientemente boa para empregar o verbo 'cantar'. Logo, os casos de implicatura conversacional particularizada são aqueles 'em que uma implicatura é veiculada ao dizer-se $p$ numa ocasião particular em virtude de características especiais do contexto, casos em que não se poderia sugerir que uma implicatura deste tipo é NORMALMENTE veiculada ao enunciar-se p' (GRICE, 1967, p. 100).

Por outro lado, a implicatura conversacional generalizada, à qual nos detemos nesta pesquisa, não é acionada via contexto, senão decorrente da combinação de palavras que pode acarretar uma implicatura na ausência de circunstâncias especiais. É o caso das implicaturas que podem ser acionadas com os numerais e com determinados termos escalares, como 'alguns' e 'ou', entre outras.

\section{A INTERFACE SEMÂNTICA/PRAGMÁTICA NA INTERPRETAÇÃO DOS NUMERAIS}

Para tratar dessa abordagem, apresentaremos a discussão proposta pelos neo-griceanos, tomando como ponto de partida o trabalho Generalized Conversational Implicature and 
the Semantics/Pragmatics Interface (LEVINSON, 2000). Nesse trabalho, o autor propõe uma reconfiguração na arquitetura clássica de Grice, defendendo que "generalized conversational implicatures seem to play a role in the assignment of truthconditional content." (LEVINSON, 2000, p. 166).

É importante mencionar que, além de Levinson, Chierchia (2001) também contesta a arquitetura clássica, propondo que as implicaturas escalares são processadas simultaneamente com as condições de verdade "Implicatures are not computed after truth-conditions of (roof) sentences have been figured out; they are computed phrase by phrase in tandem with truth-conditions (or whatever compositional semantics computes)." (CHIERCHIA, 2001, p.3).

Não queremos afirmar, contudo, que Levinson e Chierchia apresentem teorias convergentes. No entanto, observa-se que ambos os autores defendem um novo desenho da interface Semântica/Pragmática, buscando indícios de que a arquitetura ortodoxa não funciona. Vejamos a análise que Levinson (2000) faz de dados como:

(5) João tem três filhos.

(5') João tem exatamente três filhos.

O exemplo em (5') é um raciocínio não-monotônico de (5), isto é, pragmático. Se João tem, na verdade, quatro filhos, cancelo a implicatura (5'), mas não nego a proposição (5). Vale destacar que uma das características da implicatura é ser cancelável, o que a difere do acarretamento. Dessa forma, para Levinson, há dois módulos, um semântico (monotônico), e outro pragmático (não-monotônicos), sendo que este se caracteriza por raciocínios canceláveis.

Segundo Levinson, então, interpretamos um numeral, paralelamente, via semântica e via pragmática. Tomemos o número 'três' como exemplo: cf. a literatura, a interpretação semântica dos números diz que 'três' significa 'pelo menos três'. A interpretação de 'exatamente três' é pragmática, isto é, obtida através de uma implicatura conversacional generalizada, que não está ligada diretamente ao o que é dito, e sim, conectada a traços gerais do discurso. Vejamos o exemplo abaixo:

(6) Leve essas três bebidas para as três pessoas lá em cima, e essas quatro, para aquelas quatro pessoas lá.

Se o numeral 'três' significa 'pelo menos três', na ausência de gestos, a palavra 'três' pode indicar tanto o conjunto de três bebidas e pessoas quanto o de quatro - uma vez que quatro implica pelo menos três. Entretanto, o enunciado é válido e, provavelmente, não causará nenhum estranhamento, pois o ouvinte aciona a implicatura conversacional e interpreta o dito como 'exatamente três' e 'exatamente quatro'. Observa-se, portanto, que a implicatura é essencial para encontrar o referente no mundo, e, segundo Levinson (2000), necessária para a atribuição do valor de verdade. Logo, ela não pode ser processada após o proferimento e nem globalmente.

Portanto, em oposição ao círculo de Grice, Levinson (2000) argumenta que as implicaturas conversacionais não são simplesmente acionadas depois da interpretação semântica, como se propõe no modelo tradicional, senão simultaneamente. Para o autor, 
as implicaturas são necessárias para as condições de verdade de uma proposição, motivo pelo qual ele as chama de implicaturas intrometidas. A sentença abaixo, segundo Levinson (2000), serve como argumento para fundamentar essa idéia:

(7) O homem com duas crianças por perto é meu irmão. E o homem com três crianças por perto é meu cunhado.

Semanticamente essa sentença não poderia ser processada, pois não conseguimos identificar um único referente para cada expressão definida ${ }^{4}$ - 'o homem com duas crianças' e o 'homem com três crianças'. Como 'duas crianças' e 'três crianças' significam 'pelo menos duas' e 'pelo menos três', respectivamente, o homem com duas crianças pode ser tanto meu irmão como meu cunhado. No entanto, a nossa intuição é de que, na situação descrita, essa proposição é verdadeira. A explicação de Levinson é que, antes de identificarmos o referente no mundo, passamos pela intrusão (implicatura) de 'exatamente dois' e 'exatamente três', isto é, interpretamos a frase como verdadeira via implicatura de 'exatamente'.

Vale destacar, ainda, outros autores que defendem a interferência pragmática na interpretação dos numerais. Segundo Huang et al. (2005), além de Levinson (2000), Horn (1972; 1989) e Gadzar (1979) sustentam que, embora os números recebam, freqüentemente, a interpretação exata, na verdade, seu significado lógico é 'pelo menos'. Para sustentar essa afirmação, Huang apresenta o raciocínio desses autores a partir dos exemplos abaixo:

(8) A: Do you have two children?

$\mathrm{B}$ : Yes, in fact I have three.

(9) Bonnie: I need to borrow two chairs. Do you know where I could get them?

David: Sure, I've got two chairs.

Em (8A), o significado de dois parece 'exatamente dois'; no entanto, o ouvinte (8B) aceita que dois significa 'pelo menos dois'. O mesmo ocorre em (9): ainda que David afirme ter duas cadeiras, não causaria nenhuma surpresa saber que ele tem três ou mais (HUANG et al., 2005, p. 3).

\section{A POLISSEMIA DOS NUMERAIS}

Em Take five: the meaning and use of a number word, Geurts (2006) contesta a teoria dos neo-griceanos ${ }^{5}$ de que o significado dos números é 'at least $x$ '. Segundo o autor, o significado primário de um número x é 'exatamente x', e o sentido de 'pelo menos' é obtido via derivação semântica. Nesta perspectiva, não há inferências pragmáticas.

Geurts aponta dois problemas acerca das discussões sobre o significado dos números: i) a falta da apresentação de uma estrutura explícita da semântica composicional; ii) a

\footnotetext{
${ }^{4}$ Pressuposição de existência e unidade disparada pelo artigo definido: existe um e apenas um x para uma expressão definida.

${ }^{5}$ Ao falar dos neo-griceanos, Geurts está se referindo a Horn, Levinson e Winter. No entanto, segundo o autor, por reconhecer os problemas da abordagem, Horn a abandona anos depois.
} 
atribuição de apenas um significado ao numeral. Considerando que cinco, por exemplo, pode aparecer em diferentes contextos, é natural que cinco apresente diferentes significados: 'Cinco é o resultado da soma de três mais dois' (aritmético); 'Cinco patos entraram na sala' (quantificador); 'Estes são cinco patos' (predicativo); 'As cinco garotas' (adjetivo); etc. (GEURTS, 2006, p. 311-313).

O número, portanto, como outros itens lexicais, é polissêmico, isto é, apresenta vários significados relacionados; em alguns usos, é gerada a interpretação de 'exatamente', em outros, não. A polissemia, segundo Geurts, ocorre via regras de mudanças de tipo semântico (type shifting). Isso quer dizer que um determinado item lexical, dependendo do contexto gramatical em que ocorre, pode ser usado com sentidos diferentes, como, por exemplo, no sentido predicativo ou de quantificador, como podemos ver nos exemplos abaixo:

(10) Os turistas reclamaram. $\rightarrow$ quantificador $\exists \mathrm{x}[$ turista $(\mathrm{x}) \wedge$ reclamar $(\mathrm{x})]$

(11) Eles são turistas. $\rightarrow$ predicado $\quad \mathrm{x}[$ turista $(\mathrm{x})]($ they)

Com a aplicação de regras de type shifting, podemos de um sentido derivar o outro. Supondo que o sentido primário de uma palavra como 'turista' seja o de predicado, podemos chegar ao sentido de quantificador com o uso da regra de Fechamento Existencial (Existential Closure), em que o quantificador combina com um predicado para formar uma proposição.

$$
\lambda x[\operatorname{turista}(x)] \rightarrow \lambda P \exists x[\operatorname{turista}(x) \wedge P(x)]
$$

Se considerarmos que o sentido primário é o de quantificador, podemos derivar o sentido predicativo através da regra de Abaixamento do Quantificador (Quantifier Lowering).

$$
\lambda P \exists x(\operatorname{turista}(x) \wedge P(x)] \rightarrow \lambda x[\operatorname{turista}(x)]
$$

Assim, vemos que uma palavra como 'turista' é polissêmica quanto à função de predicativo ou de quantificador. O mesmo pode ocorrer com os números. A questão, então, é: qual é o sentido primário e qual é o derivado? Para Geurts, na função de quantificador, o sentido primário de três, por exemplo, é 'exatamente três'. Aplicandose a regra de Quantifier Lowering, deriva-se o uso predicativo, também com o sentido de 'exatamente'. Desse sentido predicativo, através da aplicação da regra de Existential Closure, origina-se o sentido de 'pelo menos' - enquanto quantificador. Em outras palavras, três é polissêmico entre os sentidos de predicado e de quantificador: o sentido primário é 'exatamente' e o sentido de 'pelo menos' é derivado. Como vemos, ao contrário da proposta dos neo-griceneanos, trata-se de derivação semântica e não de pragmática.

Geurts discorre sobre outras abordagens, nas quais não nos deteremos neste trabalho. No entanto, apresentamos um quadro esquemático das "teorias em quatro sabores" apresentadas pelo autor. 
QUADRO 1: A interpretação do numeral: teorias em quatro sabores (GEURTS, 2006, p. 317)

\begin{tabular}{|c|c|c|}
\hline & Sentido predicativo & Sentido de quantificador \\
\hline Teoria da Baunilha & $\begin{array}{c}\geq \\
\text { (pelo menos) }\end{array}$ & $\begin{array}{c}\geq \\
(\text { pelo menos) }\end{array}$ \\
\hline Teoria do Morango & $\begin{array}{c}= \\
\text { (exatamente) }^{6}\end{array}$ & $\begin{array}{c}= \\
\text { (pelo menos) }\end{array}$ \\
\hline Teoria do Caramelo & $\begin{array}{c}= \\
\text { (exatamente) }\end{array}$ & $\begin{array}{c}= \\
\text { (exatamente) }\end{array}$ \\
\hline Teoria do Chocolate & $\begin{array}{c}= \\
\text { (exatamente) }\end{array}$ & $\begin{array}{c}=, \geq \\
\text { (exatamente, pelo menos) }\end{array}$ \\
\hline
\end{tabular}

Analisemos as quatro teorias apresentadas por Geurts a partir dos exemplos abaixo:

(12) Estas são cinco vacas.

Então: estas são quatro vacas.

(13) Cinco vacas mugiram.

Então: quatro vacas mugiram.

A teoria da baunilha, através da qual, Geurts se refere a Levinson (2000), é a única que defende a validade de (12) e (13) - cinco significa 'pelo menos quatro', em ambos os sentidos. Por outro lado, a teoria do caramelo é a única que não defende a validade de (13), o que é menos claro, segundo Geurts (2006, p. 317, 318), pois se havia cinco vacas mugindo, deve ser verdade que havia quatro vacas, três vacas, etc. A teoria do morango e do chocolate aproximam-se ao admitir o sentido exato do numeral como predicativo e como quantificador. No entanto, esta é a única a reconhecer que diferentes funções favorecem diferentes interpretações: cinco como predicativo significa 'exatamente cinco'; como quantificador, admite a interpretação 'pelo menos cinco', embora o sentido primário seja também 'exatamente cinco'.

Logo, segundo Geurts, a teoria do chocolate é a única que dá conta de diferenciar o sentido entre predicativo e quantificador, isto é, mostrar que os números são polissêmicos e que sua polissemia pode ser captada através da aplicação de regras type shifting, isto é, enquanto o numeral com sentido de predicativo admite exclusivamente a interpretação de 'exatamente', com sentido de quantificador, admite (porém não estabelece) a interpretação de 'pelo menos'. Assim, segundo a teoria do chocolate, defendida por Geurts, aceita-se:

(14) Cinco cavalos pularam a cerca.

Então: quatro cavalos pularam a cerca.

mas, não se aceita:

(15) Estes são cinco cavalos.

Então: estes são quatro cavalos.

\footnotetext{
${ }^{6} \mathrm{O}$ negrito marca o sentido primário.
} 


\section{TESTE SOBRE A INTERPRETAÇÃO DOS NÚMEROS}

\subsection{A inclusão de crianças e adultos}

Segundo diversas teorias, crianças e adultos interpretam de maneira distinta termos escalares. Noveck (2001) argumenta, através da análise de trabalhos prévios, que as crianças são mais lógicas que os adultos, porque elas não fazem implicaturas.

Smith (1980 apud NOVECK, 2001), por exemplo, corrobora a hipótese de que as crianças têm dificuldade em fazer implicaturas. Em seu teste, a tarefa à qual as crianças eram submetidas consistia em responder perguntas como 'alguns pássaros têm asas'. Participantes de quatro a sete anos tratavam o quantificador algum como compatível a tudo. O teste mostra, portanto, que as crianças tendem a ser lógicas. É importante destacar que, na interpretação pragmática (não-monotônica), some não é compatível com all. Logo, podemos inferir que a interpretação pragmática não aparece na fase infantil.

Ao analisarem a interpretação de conectivos como or (ou), Braine e Rumain (1981 apud NOVECK, 2001) concluem que a faixa-etária de sete a nove anos favorece a interpretação lógica do or ( $p$ or $q$, ou ambos). Por outro lado, os resultados mostraram que os adultos tendem a favorecer a interpretação do ou exclusivo. Temos, então, mais um argumento a favor da tese de que crianças tendem a fazer interpretações lógicas, uma vez que a interpretação monotônica do conectivo ou é a inclusiva, e a interpretação não-monotônica é exclusiva.

Considerando que, segundo a literatura, as crianças tendem a ser mais lógicas que adultos, Noveck (2001) prevê que os resultados de sua análise a respeito da interpretação do modal might corroborem com essa hipótese. Ao propor sentenças como 'There might be a parrot in the box', na condição de que, de fato, havia um papagaio na caixa, Noveck constatou que $80 \%$ das crianças aceitaram a sentença como verdadeira, sendo o índice de aceite dos adultos de apenas 35\%. Verifica-se, portanto, que a interpretação pragmática (might não é compatível com must) aparece em índice muito mais elevado nos dados dos adultos do que das crianças.

Tais testes empíricos mostram que crianças interpretam termos escalares, como some e or, de maneira lógica e, com o avanço da idade, passam a fazer interpretações pragmáticas. Assim, a análise dessas discussões justifica a inclusão de dados de crianças e adultos neste trabalho, pois, desta forma, poderemos verificar se, na interpretação dos numerais, a implicatura entra em cena em ambos os resultados ou não. Se não houver diferença entre adultos e crianças, teremos um indício de que não há implicatura para os numerais, o que favoreceria a hipótese de Geurts.

\subsection{Metodologia}

Considerando as teorias supracitadas, elaboramos um teste a fim de verificar qual a interpretação que crianças e adultos fazem dos numerais. A hipótese é que, se a teoria de Geurts (2006) se confirma, não haverá discrepância entre os resultados obtidos no teste aplicado a crianças e adultos - ambos interpretarão os numerais conforme o contexto. Contudo, se Levinson (2000) tem razão, a interpretação das crianças deverá se 
direcionar à interpretação lógica (pelo menos) e a dos adultos, à interpretação pragmática (exatamente), ou seja, os resultados não serão coincidentes.

Para tanto, selecionamos quatorze crianças de seis anos de idade (sete do sexo feminino e sete do sexo masculino), alunos da educação infantil da creche Orlandina Cordeiro, situada no bairro Monte Verde, na cidade de Florianópolis.

Antes da aplicação do teste, cada criança passou (individualmente) por um treinamento para que pudéssemos verificar o domínio dos numerais, bem como a compreensão do comando. Todas as ações demonstradas para a criança eram introduzidas por uma boneca de fantoche, isto é, a criança mantinha diálogo com a boneca e não com as autoras. Antes do treinamento, portanto, a boneca se apresentava e mantinha um breve diálogo com as crianças, levantando questões como: 'Você conhece bem os animais?'; 'Você tem animais em casa?'; (...) 'Vamos ver se você conhece esses bichinhos que eu vou te apresentar'; etc. É importante destacar que todas as cenas eram compostas por fantoches de animais (porco, jacaré, cachorro, cavalo e coelho). A seguir apresentamos as frases do treinamento:

(1) Aqui tem três porquinhos. (mostrando três porquinhos)

(2) Os porquinhos são azuis. (mostrando porquinhos rosa)

(3) Aqui tem cinco bichinhos. (mostrando cinco bichinhos)

A criança era orientada a dizer sim quando a frase dita pela boneca estava correta, e não, quando estava incorreta. Após o treinamento, a boneca continuava conversando com a criança enquanto uma das autoras ia mudando a cena de acordo com as frases.

Nas seções a seguir, apresentaremos as frases que compõem o teste, ressaltando que contemplamos os dois sentidos dos numerais discutidos por Geurts:

(4) sentido predicativo: $\quad$ Estes são três cavalos. (mostrando quatro cavalos)

(5) sentido quantificador:

de Dois cavalos pularam a cerca.

(mostrando quatro cavalos pulando a cerca)

Para evitar que o indivíduo percebesse o tema do teste (os numerais), intercalamos os animais e incluímos sentenças sem nenhuma relação com números, a saber:

(6) Aqui tem cachorros. (mostrando jacarés)

(7) Os coelhos são dentuços. (mostrando coelhos dentuços)

(8) Esses jacarés são verdes (mostrando jacarés verdes)

(9) Os cavalos são verdes. (mostrando cavalos marrons) 
A aplicação do teste com os adultos não se afasta do modelo aplicado com as crianças: as cenas e as frases eram as mesmas. Desta vez, contudo, as frases eram apresentadas por uma das autoras, dispensando o uso da boneca.

Foram selecionados quatorze indivíduos, sete de cada sexo, considerando o mesmo nível de escolaridade (superior completo) e a mesma faixa-etária (20 a 30 anos). Estes eram convidados a participarem de um teste (individual) de cinco minutos, conscientes de que o objetivo só seria revelado na conclusão da atividade. Quanto à formação, decidimos não contemplar apenas os Cursos de Letras e Matemática, na hipótese de que estes pudessem perceber o objetivo do teste. ${ }^{7}$

\subsection{Análise dos resultados}

\subsubsection{Teste com crianças}

Conforme mencionado, o teste foi aplicado a sete meninos e sete meninas com a mesma faixa-etária e mesmo nível de escolaridade. Os resultados obtidos em ambos os sexos se aproximam. Apresentá-los-emos a seguir, dividindo as sentenças de acordo com o sentido dos numerais: predicativo ou quantificador.

\subsubsection{Numerais predicativos}

Os resultados mostram que, na função de predicativo, as crianças tendem a interpretar os numerais como 'exatamente' e não como 'pelo menos'. Vejamos as situações:

TABELA 1: Número e percentual de crianças que aceitaram a interpretação de 'pelo menos' do numeral como predicado

\begin{tabular}{|c|c|c|c|}
\hline Sentenças & Meninos & Meninas & Total \\
\hline $\begin{array}{c}\text { (1) Estes são três cavalos. } \\
\text { (mostrando quatro) }\end{array}$ & $\begin{array}{c}0 \\
\mathbf{( 0 \% )}\end{array}$ & $\begin{array}{c}1 \\
\mathbf{( 1 4 , 2 \% )}\end{array}$ & 1 \\
\hline $\begin{array}{c}\text { (2) Estes são dois jacarés. } \\
\text { (mostrando três) }\end{array}$ & $\begin{array}{c}\mathbf{0} \% \\
\mathbf{( 0 \% )}\end{array}$ & $\begin{array}{c}0 \\
\mathbf{( 0 \% )}\end{array}$ & 0 \\
\hline $\begin{array}{c}\text { (3) Estes são dois cachorros. } \\
\text { (mostrando três) }\end{array}$ & 0 & 0 & 0 \\
\hline $\begin{array}{c}\text { (4) Aqui tem três coelhos. } \\
\text { (mostrando quatro) }\end{array}$ & $\mathbf{( 0 \% )}$ & 0 & 0 \\
\hline Total & $\mathbf{( 0 \% )}$ & $\mathbf{( 0 \% )}$ & 1 \\
\hline
\end{tabular}

Sabemos que havendo quatro cavalos, há, segundo a interpretação semântica, 'pelo menos três' cavalos. No entanto, as crianças consideradas no teste parecem não ter esta interpretação, visto que as proposições acima não foram aceitas como verdadeiras. As crianças interpretaram três cavalos, por exemplo, como 'exatamente três'. Apenas uma menina aceitou como verdadeira a situação em (1), não aceitando, contudo, as proposições de 2 a 4 .

\footnotetext{
${ }^{7}$ Lembrando, ainda, que os participantes não tinham contato uns com os outros: as crianças, após a participação no teste, iam para a sala de vídeo - ambiente diferente do que estavam os colegas -, e os participantes adultos não se conheciam.
} 
Logo, até aqui, nossos resultados se afastam da teoria de Levinson (2000) e dois pontos devem ser lembrados a fim de sustentar esta afirmação: i) crianças são lógicas, isto é, têm dificuldade em interpretar implicatura; ii) o significado lógico dos números é 'pelo menos'. Bem, se o significado lógico dos numerais é 'pelo menos' e crianças tendem a ser lógicas, o esperado seria que as crianças aceitassem as sentenças de 1 a 4 como verdadeiras, uma vez que 'três' cavalos significa (semanticamente) 'pelo menos dois' cavalos e 'pelo menos um' cavalo. Contudo, não é o que observamos; nas sentenças de 1 a 4, nas quais os numerais aparecem como predicativos, as crianças tiveram a interpretação de 'exatamente'.

Quanto à teoria sobre a polissemia dos numerais, confirmamos, a priori, o estudo de Geurts (2006): numerais no sentido predicativo não admitem a interpretação de "pelo menos" - crianças parecem não aceitar que, havendo quatro cavalos, há pelo menos três, pelo menos dois, etc. Contudo, ainda é cedo para chegarmos a tal conclusão.

\subsubsection{Numerais quantificadores}

A tabela a seguir mostra os resultados da interpretação que crianças fazem dos números como quantificadores.

TABELA 2: Número e percentual de crianças que aceitaram a interpretação de 'pelo menos' do numeral como quantificador

\begin{tabular}{|c|c|c|c|}
\hline Sentenças & Meninos & Meninas & Total \\
\hline $\begin{array}{l}\text { (5) Três coelhos têm olhos vermelhos } \\
\text { (mostrando quatro) }\end{array}$ & $\begin{array}{c}5 \\
(83,33 \%)\end{array}$ & $\begin{array}{c}5 \\
(71,42 \%)\end{array}$ & 10 \\
\hline $\begin{array}{l}\text { (6) Dois cachorros mexeram o rabinho } \\
\text { (mostrando três) }\end{array}$ & $\begin{array}{c}3 \\
(50 \%)\end{array}$ & $\begin{array}{c}3 \\
(42,85 \%)\end{array}$ & 6 \\
\hline $\begin{array}{l}\text { (7) Dois jacarés têm dentes brancos. } \\
\text { (mostrando três) }\end{array}$ & $\begin{array}{c}3 \\
(50 \%)\end{array}$ & $\begin{array}{c}4 \\
(57,14 \%)\end{array}$ & 7 \\
\hline $\begin{array}{l}\text { (8) Dois cavalos pularam a cerca } \\
\text { (mostrando três) }\end{array}$ & $\begin{array}{c}2 \\
(33,33 \%)\end{array}$ & $\begin{array}{c}2 \\
(28,57 \%)\end{array}$ & 4 \\
\hline Total & 13 & 14 & 27 \\
\hline
\end{tabular}

Observamos, primeiramente, que parece não haver diferença nos resultados dos meninos e das meninas quanto à interpretação do numeral como quantificador. Em ambos os casos, aceita-se melhor a situação em (5) do que em (8).

Tal diferença poderia ser justificada pelo fato de que, diferente das demais situações, na frase em (8), a criança observava os quatro cavalos pulando a cerca um a um. Talvez, por isso, as crianças estivessem atentas ao número e à ação. Esclarecendo: ao ouvir 'Três coelhos têm olhos vermelhos', e ver, de maneira simultânea, quatro coelhos de olhos vermelhos, é possível que a criança esteja atenta apenas à cor dos olhos dos coelhos. O mesmo ocorreria em: vendo três cachorros mexendo o rabo simultaneamente e tendo que responder se é verdade que 'Dois cachorros mexeram o rabinho', a criança diria que sim, pois ela está concentrada na ação e não no número. Por outro lado, vendo três cavalos pulando a cerca, um de cada vez, a criança poderia estar contando-os à medida que observava a ação. 
Essa hipótese pode justificar a diferença significativa entre as situações (5) e (8). Nesta, média de $30 \%$ de assentimento da interpretação de 'pelo menos'; naquela, média de $80 \%$.

Desconsiderando essa conjetura, aceitaríamos a afirmação de Geurts: o numeral na função de quantificador admite a interpretação de 'pelo menos', diferente do que observamos nas proposições cujos numerais tinham sentido de predicativo.

\subsubsection{Teste com adultos}

Os resultados obtidos nesta etapa foram similares àqueles obtidos com as crianças e isso favorece a aceitação da teoria de Geurts (2006) em detrimento da teoria neo-griceana. Apresentamos, a seguir, como os adultos interpretaram os números nos contextos de predicado e de quantificador.

\subsubsection{Numerais predicativos}

Assim como as crianças, os adultos tendem a interpretar os números na função de predicativo como 'exatamente'. As mulheres foram unânimes em não aceitar a frase que não correspondesse exatamente ao numeral que estava sendo apresentado na cena. Vejamos a tabela com os resultados obtidos nesse teste:

TABELA 3: Número e percentual de adultos que aceitaram a interpretação de 'pelo menos' do numeral como predicado

\begin{tabular}{|c|c|c|c|}
\hline Sentenças & Homens & Mulheres & Total \\
\hline $\begin{array}{l}\text { (1) Estes são três cavalos. } \\
\text { (mostrando quatro) }\end{array}$ & $\begin{array}{c}0 \\
(0 \%)\end{array}$ & $\begin{array}{c}0 \\
(0 \%)\end{array}$ & 0 \\
\hline $\begin{array}{l}\text { (2) Estes são dois jacarés. } \\
\text { (mostrando três) }\end{array}$ & $\begin{array}{c}0 \\
(0 \%)\end{array}$ & $\begin{array}{c}0 \\
(0 \%)\end{array}$ & 0 \\
\hline $\begin{array}{l}\text { (3) Estes são dois cachorros. } \\
\text { (mostrando três) }\end{array}$ & $\begin{array}{c}0 \\
(0 \%)\end{array}$ & $\begin{array}{c}0 \\
(0 \%)\end{array}$ & 0 \\
\hline $\begin{array}{l}\text { (4) Aqui tem três coelhos. } \\
\text { (mostrando quatro) }\end{array}$ & $\begin{array}{c}1 \\
(\mathbf{1 6 , 6 )}\end{array}$ & $\begin{array}{c}0 \\
(0 \%)\end{array}$ & 1 \\
\hline Total & 1 & 0 & 1 \\
\hline
\end{tabular}

Observando a tabela acima, vemos que a interpretação de 'exatamente' foi praticamente unânime. Apenas um homem aceitou a interpretação de 'pelo menos' para (4). Essa escolha talvez se deva ao fato de (4) ter sido a última frase. Suspeitamos que o falante, após ter analisado as demais sentenças, inclusive as com sentido de quantificador, já que elas estavam misturadas, tenha "desconfiado" do teste e, por isso, disse sim. É interessante mencionar que, nesses resultados, estamos considerando apenas seis homens, pois um dos informantes disse sim para todas as sentenças a partir da segunda frase com numeral, a saber, 'Três coelhos têm olhos vermelhos' - pedindo, no final do teste, para corrigir a primeira, dizendo que ela também era verdadeira. Ficou claro que ele percebeu a intenção do teste. Logo, seus dados foram excluídos da análise.

Até aqui, observamos que a interpretação dos numerais feita por crianças e adultos não se distingue: apenas uma criança e um adulto aceitaram o significado de 'pelo menos' 
para o numeral na função de predicativo. O percentual de aceitação em ambos os casos é de $7,1 \%$ e $7,6 \%,{ }^{8}$ respectivamente, o que parece evidenciar que, de fato, o número predicativo não possibilita a interpretação lógica neo-griceana de 'pelo menos'. Sendo assim, já é possível argumentar contra essa abordagem, visto que, se crianças são lógicas, o esperado é que o índice de aceitação das sentenças fosse mais elevado que dos adultos; não é o que verificamos.

\subsubsection{Numerais quantificadores}

Novamente, a interpretação dos adultos foi similar à das crianças, o que corrobora a hipótese de que a interpretação dos numerais não envolve procedimentos pragmáticos. Houve $50 \%$ de aceitação das frases por parte das mulheres e $67,8 \%$, dos homens. Isso significa dizer que a interpretação de 'pelo menos' é aceita em frases em que o numeral tem sentido de quantificador.

Contudo, ao compararmos a aceitação das frases com a tabela referente ao número e percentual de aceitação por parte das crianças, encontramos algumas diferenças:

TABELA 4: Número e percentual de adultos que aceitaram a interpretação de pelo menos do numeral como quantificador

\begin{tabular}{|c|c|c|c|}
\hline Sentenças & Homens & Mulheres & Total \\
\hline $\begin{array}{l}\text { (5) Três coelhos têm olhos vermelhos } \\
\text { (mostrando quatro) }\end{array}$ & $\begin{array}{c}2 \\
(28,57 \%)\end{array}$ & $\begin{array}{c}2 \\
(\mathbf{2 8 , 5 7} \%)\end{array}$ & 4 \\
\hline $\begin{array}{l}\text { (6) Dois cachorros mexeram o rabinho } \\
\text { (mostrando três) }\end{array}$ & $\begin{array}{c}4 \\
(57,14 \%)\end{array}$ & $\begin{array}{c}4 \\
(57,14 \%)\end{array}$ & 8 \\
\hline $\begin{array}{l}\text { (7) Dois jacarés têm dentes brancos. } \\
\text { (mostrando três) }\end{array}$ & $\begin{array}{c}6 \\
(85,71 \%)\end{array}$ & $\begin{array}{c}5 \\
(71,42 \%)\end{array}$ & 11 \\
\hline $\begin{array}{l}\text { (8) Dois cavalos pularam a cerca } \\
\text { (mostrando três) }\end{array}$ & $\begin{array}{c}4 \\
(57,14 \%)\end{array}$ & $\begin{array}{c}2 \\
(28,57 \%)\end{array}$ & 6 \\
\hline Total & 16 & 13 & 29 \\
\hline
\end{tabular}

Percebemos que a frase (5) - a mais aceita pelas crianças com a interpretação de 'pelo menos' - foi a menos aceita pelos adultos. Já nas frases (6) e (7), os adultos fizeram essa interpretação em percentuais maiores do que as crianças, especialmente em relação à sentença (7). A frase (8), por sua vez, teve o índice de aceitação das mulheres igual ao das crianças, porém a aceitação dos homens foi maior. Aparentemente, não encontramos uma hipótese que justifique a diferença de interpretação entre as frases, em especial de 'Dois jacarés têm dentes brancos', que teve um alto número de aceitação comparada às demais. Acreditamos que a escolha por uma ou outra interpretação seja pragmática e não temos como saber quais foram os mecanismos acionados,

Apesar das diferenças entre as frases, o total de aceitação de 'pelos menos' em contexto de quantificador foi bastante próximo - 28 para as crianças e 29 para os adultos. Esses números correspondem a $87,5 \%$ e $90,62 \%$, respectivamente. São índices relativamente altos e mostram que a interpretação do numeral em posição predicativa e quantificadora

\footnotetext{
${ }^{8}$ Percentual calculado a partir da soma total de crianças (14) e adultos (13).
} 
é diferente. Isso nos dá margem para aceitar a proposta de Geurts, que diz que o número é polissêmico, isto é, admite mais de uma interpretação dependendo do contexto em que se encontra.

\section{CONCLUSÃo}

Os resultados do nosso experimento mostram que a teoria de Levinson (2000), bem como de outros pesquisadores neo-griceanos, é contestável no que se refere à interpretação dos numerais. O primeiro aspecto que sustenta essa afirmação é a proximidade entre os resultados obtidos no teste com crianças e adultos.

Considerando que as crianças fazem interpretações lógicas e adultos fazem implicatura, o esperado seria que os resultados fossem discrepantes, uma vez que a interpretação lógica dos numerais é 'pelo menos' e a interpretação pragmática é 'exatamente', isto é, crianças e adultos interpretariam de maneira diferente as sentenças com numerais, caso a abordagem neo-griceana se sustentasse.

Nossos resultados parecem favorecer a aceitação da abordagem proposta por Geurts (2006): números são polissêmicos, ou seja, diferentes contextos favorecem diferentes interpretações. Logo, segundo este autor, enquanto predicado, os numerais são interpretados como 'exatamente $\mathrm{x}$ ', e, enquanto quantificadores, podem ser interpretados tanto como 'exatamente $x$ ' ou 'pelo menos $x$ ', sendo a segunda interpretação derivada da primeira. Essa explicação dá conta da diferença de tratamento que nossos informantes deram aos dois grupos de frases, o que não é possível a partir da proposta de Levinson (2000).

Se aceitássemos a proposta neo-griceana, teríamos que admitir que crianças e adultos fazem implicatura quando o numeral aparece no sentido predicativo, pois a interpretação de 'pelo menos' foi rejeitada. No entanto, segundo a literatura, crianças tendem a ser lógicas, isto é, têm dificuldade de fazer implicatura - mecanismo que aparece com o passar dos anos.

Vimos, por outro lado, que, nas frases cujo numeral tem sentido quantificado, nem sempre a implicatura foi acionada (aproximadamente em 50\% dos casos), permanecendo muitas vezes a interpretação de 'pelo menos'. Por que, em um contexto, a implicatura é acionada quase em $100 \%$ das ocorrências e em outro não? A proposta de Levinson (2000) não traz uma resposta para essa questão, pois a teoria diz apenas que o significado básico do numeral é 'pelo menos $x$ ' e, via implicatura, isto é, pragmaticamente, atribuímos o sentido de 'exatamente x'. Talvez a resposta seja, justamente, admitir que a interpretação dos numerais não envolve implicatura, ou seja, posicionar-se a favor da teoria de Geurts, já que observamos que os números são interpretados de maneira diferente conforme o contexto em que estão inseridos, não dependendo, assim, de inferências pragmáticas.

Por fim, destacamos que a amostra utilizada nesta pesquisa é consideravelmente pequena, o que tornaria um estudo mais amplo, com maior número de dados, necessário para afirmações mais categóricas a respeito da teoria dos autores discutida nas seções anteriores. 


\section{REFERÊNCIAS}

CHIERCHIA, J. Scalar implicatures, polarity phenomena, and the Syntax/Pragmatics interface. University of Milan: Bicocca, 2001.

Semântica. São Paulo: Unicamp, 2003.

GEURTS, Barts. Take "five": the meaning use of a number word. In: VOGELEER \& TASMOWSKI. Non-definiteness and Plurality. Philadelphia: Benjamins, 2006. 311329.

GRICE, H. P. 1967. Logic and Conversation. In: DASCAL, M. Fundamentos Metodológicos da Lingüística, vol. IV Pragmática. Campinas: Editora da Unicamp, 1982. 81-104.

HUANG, Yi Ting; SNEDEKER, Jesse; SPELKE, Elisabeth. What exactly do numbers mean? Harvard University, $2005 . \quad$ In: http://www.wjh.harvard.edu/ lds/pdfs/Huang-Snedeker-Spelke-submitted.pdf. Acesso em setembro de 2007.

LEVINSON, Stephen C. Generalized conversational implicature and the Semantics/Pragmatics interface. In: Presumptive meanings. MIT Press, 2000.

NOVECK, Ira. When children are more logical than adults: Experimental investigations of scalar implicature. In: Cognition 78/2. Lyon: Institut des Sciences Cognitives, 2001. 165-188. 